\title{
Interleukin 18 receptor 1 gene polymorphisms are associated with asthma
}

\author{
Guohua Zhu' ${ }^{1}$, Moira KB Whyte ${ }^{2}$, Jorgen Vestbo ${ }^{3,4}$, Karin Carlsen ${ }^{5}$, Kai-Håkon Carlsen ${ }^{5}$, \\ Warren Lenney ${ }^{6}$, Michael Silverman ${ }^{7}$, Peter Helms ${ }^{8}$ and Sreekumar G Pillai ${ }^{*, 1}$
}

\begin{abstract}
${ }^{1}$ Genetics, GlaxoSmithKline, Research Triangle Park, NC, USA ${ }^{2}$ Academic Unit of Respiratory Medicine, University of Sheffield, Sheffield, UK; ${ }^{3}$ Institute of Preventive Medicine, Kommunehospitalet, Copenhagen, Denmark; ${ }^{4}$ Department of Respiratory Medicine, Hvidovre University Hospital, Hvidovre, Denmark; ${ }^{5}$ Department of Pediatrics, Ullevaal University Hospital, Oslo, Norway; ${ }^{6}$ Directorate of Child Health, Academic Department of Pediatrics, North Staffordshire Hospital, Stoke-on-Trent, UK; ${ }^{7}$ Division of Child Health, University of Leicester, Leicester, UK; ${ }^{8}$ Department of Child Health, University of Aberdeen Royal Aberdeen Children's Hospital, Aberdeen, UK
\end{abstract}

The interleukin 18 receptor (IL18R1) gene is a strong candidate gene for asthma. It has been implicated in the pathophysiology of asthma and maps to an asthma susceptibility locus on chromosome $2 q 12$. The possibility of association between polymorphisms in IL18R1 and asthma was examined by genotyping seven SNPs in 294, 342 and 100 families from Denmark, United Kingdom and Norway and conducting family-based association analyses for asthma, atopic asthma and bronchial hyper-reactivity (BHR) phenotypes. Three SNPs in IL18R1 were associated with asthma $(0.01131 \leq P \leq 0.01377)$, five with atopic asthma $(0.00066 \leq P \leq 0.00405)$ and two with BHR $(0.01450 \leq P \leq 0.03203)$ in the Danish population; two SNPs were associated with atopic asthma $(0.00397 \leq P \leq 0.01481)$ and four with BHR $(0.00435 \leq P \leq 0.03544)$ in the UK population; four SNPs showed associations with asthma $(0.00015 \leq P \leq 0.03062)$, two with atopic asthma $(0.01269 \leq P \leq 0.04042)$ and three with BHR $(0.00259 \leq P \leq 0.01401)$ in the Norwegian population; five SNPs showed associations with asthma $(0.00005 \leq P \leq 0.03744)$, five with atopic asthma $(0.00001 \leq P \leq 0.04491)$ and three with BHR $(0.03568 \leq P \leq 0.04778)$ in the combined population. Three intronic SNPs (rs1420099, rs1362348 and rs1974675) showed replicated association for at least one asthma-related phenotype. These results demonstrate significant association between polymorphisms in IL18R1 and asthma.

European Journal of Human Genetics (2008) 16, 1083-1090; doi:10.1038/ejhg.2008.67; published online 2 April 2008

Keywords: asthma; IL18R1; genetic association; haplotype analysis; replication

\section{Introduction}

Asthma is a multifactorial respiratory disease determined by interactions of multiple disease susceptibility genes and environmental factors. ${ }^{1}$ The pathophysiology of asthma is characterized by variable airway obstruction, bronchial

*Correspondence: Dr SG Pillai, Genetics, GlaxoSmithKline, 5 Moore Drive, Research Triangle Park, NC 27709, USA.

Tel: + 1919483 1815; Fax: + 1919315 0311;

E-mail: sreekumar.g.pillai@gsk.com

Received 19 October 2007; revised 5 February 2008; accepted 28 February 2008; published online 2 April 2008 hyper-reactivity (BHR) and airway inflammation caused by release of cytokines and other mediators from both immune and structural cells. ${ }^{2}$ The cytokine interleukin 18 (IL18) has been implicated in several inflammatory diseases including asthma. ${ }^{3}$ IL18 was initially identified as an interferon (IFN)- $\gamma$-inducing factor, but plays multiple IFN$\gamma$-dependent and -independent roles in the regulation of both innate and acquired immunity. It functions as a crucial regulator of IgE production through balancing the $\mathrm{T}_{\mathrm{H}}$ 1-cell- and $\mathrm{T}_{\mathrm{H}}$ 2-cell-mediated immune responses. ${ }^{4}$ In synergy with IL12, IL18 inhibits IgE expression through 
activating the $\mathrm{T}_{\mathrm{H}} 1$ cell-mediated immune responses that induce IFN- $\gamma$ expression. ${ }^{5}$ In the absence of interleukin 12 (IL12), IL18 stimulates the production of IgE through promoting the $\mathrm{T}_{\mathrm{H}} 2$ cell-mediated immune reactions that enhance the expression of interleukin 4 (IL4) and interleukin 13 (IL13). ${ }^{6,7}$

IL18 elicits its immunoregulatory functions by binding to $I L 18$ receptor (IL18R), a member of the IL1 receptor superfamily. IL18R is a heterodimer of IL18R1 and IL18R2 (also known as $I L 18 R \alpha$ and $I L 18 R \beta$ ); IL18R1 is responsible for IL18 binding and IL18R2 for initiating signal transduction. ${ }^{8,9}$ The interaction of IL18 and IL18R triggers myeloid differentiation 88 (MyD88)-dependent signal transduction pathways, including activation of $I L 1 R$-associated kinases, tumor necrosis factor receptor-associated factor 6 , and the other downstream effectors; which induces the activation of activator protein 1 and the nuclear translocation of nuclear factor $\kappa \mathrm{B}(\mathrm{NF}-\kappa \mathrm{B}),{ }^{10-13}$ which may in turn increase transcription of IL4 and IL13. ${ }^{6,7}$

Several studies have shown associations between IL18 gene variants and asthma related phenotypes, ${ }^{14-16}$ but there are no reports of association with variants in $I L 18 R$. IL18R1 is located on chromosome $2 \mathrm{q} 12,{ }^{17}$ a region containing numerous immunoregulatory genes that have shown evidence for linkage to asthma and atopic phenotypes. ${ }^{18-21}$ IL18R1 is the sole receptor transducing the important immunomodulatory effects of $I L 18$ and is thus also a good biological candidate gene for asthma.

The aim of this study was to evaluate a number of IL18R1 variants in a family-based association study by investigating a large Danish population with 294 families and 1151 subjects, together with two replication populations from the United Kingdom and Norway. Our results demonstrate significant association between IL18R1 polymorphisms and asthma-related phenotypes.

\section{Materials and methods}

Study populations and phenotypes

Primary Study Population The Denmark collection of 294 families with 1151 subjects was investigated at the
Department of Respiratory Medicine, Hvidovre University Hospital, Hvidovre, Denmark. In the selection of these families, at least two siblings with clinical asthma were required. The ascertainment procedure for the Danish collection is described elsewhere. ${ }^{22}$

Replication population A total of 342 families ascertained from the United Kingdom as a part of the Genetics of Asthma International Network (GAIN) were selected as a replication population. Four sets of samples collected from the different centers: 94 families with 401 subjects from Aberdeen, UK; 73 families with 301 subjects from Leicester, UK; 93 families with 399 subjects from Sheffield, UK and 82 families with 345 subjects from Stoke-on-Trent, UK. In the selection of these families, at least two siblings with clinical asthma were required. The ascertainment procedure for the GAIN collection is described elsewhere. ${ }^{23}$ The second replication population consisted of 100 families with 414 subjects ascertained from Norway as a part of the GAIN collection.

All subjects were evaluated using standard protocols. Baseline spirometry was performed according to American Thoracic Society criteria. Methacholine challenge test was performed on those subjects with percent-predicted $\mathrm{FEV}_{1}$ of $70 \%$ or more. A bronchodilator response test was done in those subjects where percent predicted $\mathrm{FEV}_{1}$ was less than $70 \%$. Skin prick tests were performed for a panel of common aeroallergens. The studies were approved by appropriate institutional review boards and an appropriate informed consent was obtained from each subject. The clinical characteristics of the ascertained families are listed in Table 1.

Three qualitative phenotypes were assessed: (1) asthma, a participating physician examined these patients and made a clinical diagnosis of asthma based on common asthma symptoms, medication history, lung function and skinpick tests; (2) atopic asthma was defined as asthma and at least one positive skin allergen test and (3) bronchial hyper-reactivity (BHR) was defined as a positive methacholine response $\left(\geq 20 \%\right.$ reduction in $\left.\mathrm{FEV}_{1}\right)$ at or below $8 \mathrm{mg} /$ $\mathrm{ml}$ of methacholine.

Table 1 Clinical characteristics of the study populations

\begin{tabular}{|c|c|c|c|c|c|c|}
\hline \multirow{2}{*}{ Variable } & \multicolumn{2}{|c|}{ Danish } & \multicolumn{2}{|c|}{ UK } & \multicolumn{2}{|c|}{ Norwegian } \\
\hline & $\begin{array}{l}\text { Siblings } \\
(\mathrm{n}=563)\end{array}$ & $\begin{array}{c}\text { Parents } \\
(\mathrm{n}=588)\end{array}$ & $\begin{array}{l}\text { Siblings } \\
(\mathrm{n}=762)\end{array}$ & $\begin{array}{l}\text { Parents } \\
(\mathrm{n}=684)\end{array}$ & $\begin{array}{l}\text { Siblings } \\
(\mathrm{n}=214)\end{array}$ & $\begin{array}{l}\text { Parents } \\
(\mathrm{n}=200)\end{array}$ \\
\hline $\begin{array}{l}\text { Age (years) } \pm \text { SD } \\
\text { Age of onset (years) } \pm S D \\
\text { Gender (female \%) } \\
\mathrm{FEV}_{1}(\mathrm{I}) \pm \mathrm{SD} \\
\mathrm{Log}_{10} \lg (\mathrm{ng} / \mathrm{ml}) \pm \mathrm{SD} \\
\text { One or more positive skin tests, }\end{array}$ & $\begin{array}{c}28.10 \pm 8.17 \\
12.3 \pm 1.66 \\
56.29 \\
3.48 \pm 0.94 \\
\mathrm{NA} \\
355(63.05 \%)\end{array}$ & $\begin{array}{c}54.92 \pm 10.18 \\
25.91 \pm 46.05 \\
50.00 \\
2.84 \pm 0.96 \\
\text { NA } \\
134(22.79 \%)\end{array}$ & $\begin{array}{c}14.42 \pm 4.96 \\
6.28 \pm 6.62 \\
43.10 \\
2.69 \pm 1.10 \\
2.17 \pm 1.10 \\
559(73.36 \%)\end{array}$ & $\begin{array}{c}43.70 \pm 6.52 \\
22.46 \pm 32.63 \\
50.00 \\
3.17 \pm 0.78 \\
1.72 \pm 1.64 \\
370(54.09 \%)\end{array}$ & $\begin{array}{c}14.25 \pm 6.14 \\
7.0 \pm 5.86 \\
45.90 \\
2.79 \pm 1.03 \\
2.03 \pm 0.63 \\
134(62.62 \%)\end{array}$ & $\begin{array}{c}43.46 \pm 6.56 \\
29.93 \pm 14.64 \\
50.00 \\
3.64 \pm 0.81 \\
1.69 \pm 0.65 \\
102(51.00 \%)\end{array}$ \\
\hline
\end{tabular}

Abbreviation: NA, not available. 


\section{SNP selection and genotyping}

SNPs were selected using a minor allele frequency of $>0.05$, availability and location within the gene and ease of genotyping. The IL18R1 gene is $37.2 \mathrm{~kb}$ in length and seven SNPs were selected from the NCBI SNP database (http://www.ncbi.nlm.nih.gov/projects/SNP/) to cover the gene as uniformly as possible with on average one SNP per $5.3 \mathrm{~kb}$. Their positions are listed in Table 2. These SNPs were genotyped in the three populations by a modification of the single base chain extension assay as previously described. ${ }^{24}$ Parental genotype data were used to assess Hardy-Weinberg equilibrium using an exact method. ${ }^{25}$ For each population, all SNPs were in Hardy-Weinberg equilibrium $(P$-values $>0.05)$. The PedCheck program was used to test Mendelian inconsistencies in the genotype data from each family population. ${ }^{26}$ No genotyping inconsistencies were detected.

\section{Statistical analyses}

Family-based association test (FBAT) version $1.7 .3^{27}$ was used to assess the association of each single SNP with asthma, atopic asthma and BHR. Biallelic tests were performed for SNPs under an additive genetic model. Haplotype-based association test was done using the HBAT function of the FBAT program with Monte Carlo sampling in the family data. ${ }^{28}$ Using an SNP sliding window approach (adjacent three SNPs), the results of global and haplotype-specific statistics were reported. $P$-values $<0.05$ from the analyses were considered the nominally significant levels. Since seven SNPs were evaluated, the adjusted significant $P$-values are $<0.0071$ (ie, $0.05 / 7$ ) after Bonferroni correction for multiple testing. Haplotype results were considered as nominally significant if the global $P$-values were $<0.05$. Because five haplotypes were tested, adjusted significant $P$-values were $<0.01$ (ie, $0.05 / 5$ ). In view of the high correlation between the three asthma and asthmarelated phenotypes, we chose not to correct for testing of the three phenotypes in order to avoid being overconservative. The linkage disequilibrium (LD) measures were performed using Haploview version 4.0. ${ }^{29}$ The $r^{2}$ for each pair of SNPs was calculated, and haplotype blocks were defined using the confidence-intervals algorithm described by Gabriel et al. ${ }^{30}$

\section{Results \\ Single SNP association analysis}

We evaluated seven SNPs in the IL18R1 gene; the location and characteristics of these SNPs are summarized in Table 2 and the results of single SNP association analysis are shown in Table 3. We detected significant association between SNPs within the IL18R1 gene and asthma phenotypes in all the three populations. In the Danish population, three SNPs were associated with asthma $(0.01131 \leq P \leq 0.01377)$, five with atopic asthma $(0.00066 \leq P \leq 0.00405)$ and two with BHR $(0.01450 \leq P \leq 0.03203)$. SNPs 2 (rs1420099), 4 (rs1362348), 5 (rs2058622) and 6 (rs1974675) were still significantly associated with atopic asthma after Bonferroni multiple correction. In the UK population, two SNPs were associated with atopic asthma $(0.00397 \leq P \leq 0.01481)$ and four with BHR $(0.00435 \leq P \leq 0.03544)$. SNP 6 (rs1974675) remained significantly associated with atopic asthma and BHR after multiple correction. In the Norwegian population, four SNPs were associated with asthma $\quad(0.00015 \leq P \leq 0.03062)$, two with atopic asthma $(0.01269 \leq P \leq 0.04042)$ and three with BHR (0.00259 $\leq P \leq 0.01401)$. SNPs 2 (rs1420099), 4 (rs1362348) and 6 (rs1974675) were still significantly associated with asthma after multiple testing correction, while SNPs 4 (rs1362348) and 6 (rs1974765) remained significantly associated with BHR after multiple testing correction. In the combined population, five SNPs were associated with asthma $\quad(0.00005 \leq P \leq 0.03744)$, five with atopic asthma $(0.00001 \leq P \leq 0.04491)$ and three with BHR (0.03568 $\leq P \leq 0.04778)$. SNPs 2 (rs1420099), 4 (rs1362348) and 6 (rs1974675) were significantly associated with asthma even after correction for multiple testings. The SNPs 2 (rs1420099), 4 (rs1362348), 6 (rs1974765) and 7 (rs1420094) remained significantly associated with atopic asthma after correction for multiple testing. Several SNPs showed significant replicated associations for the same phenotype in two or more populations. SNPs 2 (rs1420099), 4 (rs1362348) and 6 (rs1974675) were replicated for asthma in Danish and Norwegian populations. SNP 2 (rs1420099) was replicated for atopic asthma in Danish and UK populations; SNP 4 (rs1362348) was replicated for atopic asthma in Danish and Norwegian populations; SNP 6 (rs1974675) was replicated for atopic asthma in Danish, UK and Norwegian populations. SNP 2

Table 2 SNPs in the IL18R1 genotyped and analyzed in the study

\begin{tabular}{|c|c|c|c|c|c|c|}
\hline$S N P$ & SNP name & Position (NCBI 36) & Function & Alleles $(\mathrm{F})^{\mathrm{a}}$ in Danish & Alleles (F) in UK & Alleles (F) in Norwegian \\
\hline 1 & rs2287037 & 102345460 & Promoter & G/A (0.3994) & G/A (0.4080) & G/A (0.3987) \\
\hline 2 & rs1420099 & 102346975 & Intron & G/C (0.3159) & $\mathrm{G} / \mathrm{C}(0.3532)$ & G/C (0.3219) \\
\hline 3 & rs1420098 & 102350711 & Intron::Lariat & $\mathrm{A} / \mathrm{G}(0.4013)$ & $\mathrm{A} / \mathrm{G}(0.4097)$ & $\mathrm{A} / \mathrm{G}(0.3902)$ \\
\hline 4 & rs1362348 & 102351056 & Intron & G/C (0.3094) & $\mathrm{G} / \mathrm{C}(0.3517)$ & G/C (0.3230) \\
\hline 5 & rs2058622 & 102351856 & Intron & $\mathrm{C} / \mathrm{T}(0.2790)$ & $\mathrm{C} / \mathrm{T}(0.2346)$ & $\mathrm{C} / \mathrm{T}(0.2827)$ \\
\hline 6 & rs1974675 & 102352807 & Intron & $\mathrm{C} / \mathrm{T}(0.3156)$ & $\mathrm{C} / \mathrm{T}(0.3505)$ & $\mathrm{C} / \mathrm{T}(0.3229)$ \\
\hline 7 & rs1420094 & 102382119 & 3 prime flank & G/A (0.4238) & G/A (0.4393) & G/A (0.4404) \\
\hline
\end{tabular}

${ }^{\mathrm{a}}$ The second allele is minor allele and its frequency $(F)$. 
(rs1420099) was replicated for BHR in UK and Norwegian populations and both SNPs 4 (rs1362348) and 6 (rs1974675) were replicated for BHR in Danish, UK and Norwegian populations.

\section{Linkage disequilibrium analysis}

Figure 1 shows pair-wise $\operatorname{LD}\left(r^{2}\right)$ values for the seven SNPs in the IL18R1 gene in Danish, UK and Norwegian populations. The same two haplotype blocks were revealed in all three populations. SNPs 1 (rs2287037), 2 (rs1420099) and 3 (rs1420098) were located in the $5 \mathrm{~kb}$ block 1 and there was strong pair-wise correlation of SNPs 1 and 3 in the three populations. SNPs 4 (rs1362348), 5 (rs2058622), 6 (rs1974675) and 7 (rs1420094) were in the $31 \mathrm{~kb}$ block 2 and there was strong pair-wise correlation between SNPs 4 and 6 in the three populations. In addition, there was strong pair-wise correlation between SNPs 2 and 4 , and 4 and 6 . The positive finding from this study was mainly the associations with SNPs 2, 4 and 6. LD figures indicate these SNPs are almost in complete LD. Thus, this study identified an association of these SNPs, which are in tight LD with asthma and related phenotypes.

\section{Haplotype analysis}

To capture additional information on the LD structure and provide greater power in detecting association than was obtained from single SNP association analysis, we performed haplotype-based association analysis. The significant results of haplotype analyses of asthma, atopic asthma and BHR are listed in Table 4. In the Danish population, four adjacent SNP combinations showed significant association with asthma $(0.00735 \leq$ p-global $\leq 0.02843$ and $0.00289 \leq \mathrm{p}$-specific $\leq 0.01102)$, five haplotypes with atopic asthma $(0.00110 \leq$ p-global $\leq 0.00181$ and $0.00073 \leq$ p-specific $\leq 0.00156$ ) and one haplotype 2-3-4 with BHR (pglobal $=0.04174$ and p-specific $=0.01929$ ). Haplotype 2-34 was still significantly associated with asthma after Bonferroni multiple correction. Haplotypes 1-2-3, 2-3-4, 4-5-6 and 5-6-7 remained significantly associated with atopic asthma after multiple correction.

The significant findings of the haplotype analyses were also detected in the replication populations from the United Kingdom and Norway. In the UK population, one haplotype 4-5-6 was significantly associated with asthma (p-global $=0.03527$ and p-specific $=0.02407)$, three haplotypes with atopic asthma $(0.00942 \leq \mathrm{p}$-global $\leq 0.03891$ and $0.00839 \leq \mathrm{p}$-specific $\leq 0.03024)$ and four haplotypes with BHR $(0.00821 \leq$ p-global $\leq 0.03652$ and $0.00609 \leq$ p-specific $\leq 0.01901)$. Haplotype 4-5-6 was still significantly associated with atopic asthma and BHR after multiple correction. In the Norwegian population, five haplotypes showed significant association results with asthma $(0.00077 \leq$ p-global $\leq 0.01084$ and $0.00024 \leq$ p-specific $\leq 0.00370)$, two with atopic asthma $(0.03390 \leq$ p-global $\leq 0.04601$ and $0.01822 \leq$ p-specific $\leq 0.02049$ ) 

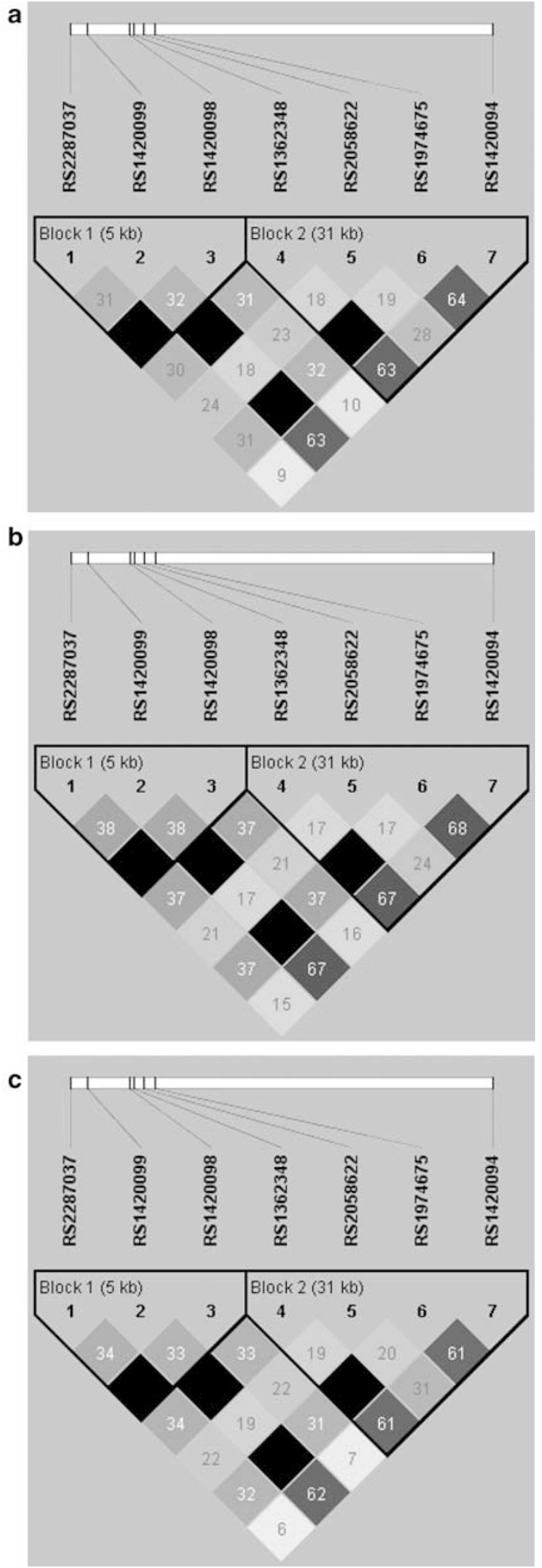

and five with BHR $(0.00317 \leq \mathrm{p}$-global $\leq 0.02657$ and $0.00166 \leq$ p-specific $\leq 0.00977$ ). Haplotypes 2-3-4, 3-4-5, 4-5-6 and 5-6-7 were still significantly associated with asthma after multiple correction, while haplotypes 2-3-4, 3-4-5 and 4-5-6 remained significantly associated with BHR after multiple correction. No stronger association was detected by haplotype analysis than single SNP analysis.

\section{Discussion}

We identified significant association between genetic variations in IL18R1 and asthma phenotypes using a family-based design in three populations, with SNPs 4 (rs1362348) and 6 (rs1974675) showing replicated evidence of association in all three populations. SNP 2 (rs1420099) showed significant association that was replicated in two populations. The results of haplotype analyses strongly supported the single marker results. SNP 1 (rs2287037), which is located in the promoter region $(-68 \mathrm{G} / \mathrm{A})$ and may function in transcriptional regulation, was associated with BHR in the UK population. The haplotype 1 (rs2287037)-2 (rs1420099)-3 (rs1420098) involving SNP 1 (rs2287037) showed significant replicated association in two populations. Two polymorphisms have previously been identified in the promoter region of the IL18R1 at positions -69 and -638 relative to the transcriptional start site. ${ }^{31}$ A three-base deletion (950del CAG) polymorphism is also reported in the promoter of the IL18R1 gene, which is generated by alternative splicing and is associated with reduced production of IFN- $\gamma$ in the Japanese population. ${ }^{32}$ We therefore postulate SNP rs2287037 (-68 G/A) may modify IL18R1 gene transcription and thus IL18 functional effects relevant to asthma.

Three genetic association studies of IL18R1 and different diseases have been reported previously. Hoffjan $e^{2} a^{33}$ did not detect significant association between a single microsatellite marker in IL18R1 and atopic dermatitis in a 154 gene association study with a population of 150 subjects. Nadif $e \mathrm{al}^{34}$ failed to demonstrate an association between a single IL18R1 variant $(-69 \mathrm{C} / \mathrm{T})$ and coal workers' pneumoconiosis in 200 subjects. Tiret et $a l^{35}$ did not observe any significant association of 10 SNPs in IL18R1 with cardiovascular disease in a population with 1288 subjects. In this study, however, we identify significant replicated associations of IL18R1 with asthma and asthma-related phenotypes in the three independent populations. Moreover, a recent study has emphasized the biological importance of

Figure 1 Linkage disequilibrium (LD) map across the IL18R1 gene region. LD block structures of seven SNPs within IL18R1 region in Danish (a), UK (b) and Norwegian (c) populations. Values of $r^{2}$ $(\times 100)$ are shown, and those squares in shades of gray, $0<r^{2}<1$ (the intensity of the gray is proportional to $r^{2}$ ). Haplotype block structure was estimated with the Haploview program. 
Table 4 Results of the haplotype-based association analyses in Danish, UK and Norwegian populations (global $P$-value $<0.05)$.

\begin{tabular}{|c|c|c|c|c|}
\hline Population-phenotype & Haplotype & Global P-value & Specific P-value & Haplotype frequency \\
\hline \multirow[t]{4}{*}{ Danish-asthma } & $1-2-3$ & 0.01954 & 0.00828 & 0.330 \\
\hline & $2-3-4$ & 0.00735 & 0.00289 & 0.331 \\
\hline & $3-4-5$ & 0.02182 & 0.00892 & 0.332 \\
\hline & $4-5-6$ & 0.02843 & 0.01102 & 0.327 \\
\hline \multirow[t]{5}{*}{ Danish-atopic asthma } & $1-2-3$ & 0.00176 & 0.00156 & 0.330 \\
\hline & $2-3-4$ & 0.00121 & 0.00150 & 0.276 \\
\hline & $3-4-5$ & 0.00181 & 0.00152 & 0.268 \\
\hline & $4-5-6$ & 0.00140 & 0.00073 & 0.327 \\
\hline & $5-6-7$ & 0.00110 & 0.00101 & 0.267 \\
\hline Danish-BHR & $2-3-4$ & 0.04174 & 0.01929 & 0.331 \\
\hline UK-asthma & $4-5-6$ & 0.03527 & 0.02407 & 0.405 \\
\hline \multirow[t]{3}{*}{ UK-atopic asthma } & $1-2-3$ & 0.04107 & 0.03024 & 0.405 \\
\hline & $4-5-6$ & 0.00942 & 0.00839 & 0.405 \\
\hline & $5-6-7$ & 0.03891 & 0.01485 & 0.352 \\
\hline \multirow[t]{4}{*}{ UK-BHR } & $1-2-3$ & 0.01386 & 0.00766 & 0.358 \\
\hline & $2-3-4$ & 0.03652 & 0.01901 & 0.407 \\
\hline & $4-5-6$ & 0.00821 & 0.00609 & 0.405 \\
\hline & $5-6-7$ & 0.01700 & 0.00963 & 0.352 \\
\hline \multirow[t]{5}{*}{ Norwegian-asthma } & $1-2-3$ & 0.01084 & 0.00370 & 0.338 \\
\hline & $2-3-4$ & 0.00262 & 0.00086 & 0.340 \\
\hline & $3-4-5$ & 0.00161 & 0.00024 & 0.344 \\
\hline & $4-5-6$ & 0.00077 & 0.00034 & 0.336 \\
\hline & $5-6-7$ & 0.00211 & 0.00053 & 0.327 \\
\hline \multirow{2}{*}{ Norwegian-atopic asthma } & $3-4-5$ & 0.04601 & 0.01822 & 0.344 \\
\hline & $4-5-6$ & 0.03390 & 0.02049 & 0.336 \\
\hline \multirow{5}{*}{ Norwegian-BHR } & $1-2-3$ & 0.01065 & 0.00521 & 0.338 \\
\hline & $2-3-4$ & 0.00880 & 0.00323 & 0.340 \\
\hline & $3-4-5$ & 0.00317 & 0.00166 & 0.344 \\
\hline & $4-5-6$ & 0.00805 & 0.00701 & 0.336 \\
\hline & $5-6-7$ & 0.02657 & 0.00977 & 0.327 \\
\hline
\end{tabular}

Haplotypes with a global $P$-value $<0.05$ are shown. Specific $P$-value represents the $P$-value of the most significant specific haplotype. Haplotype frequency represents the frequency of the most significant specific haplotype. The relative position of the SNPs in the haplotypes combinations corresponds to the SNPs ids given in Table 2.

IL18R1 in inflammatory lung disease, with marked protection of IL18R1-deficient mice from cigarette smokeinduced pulmonary inflammation. ${ }^{36}$

Association studies provide a potentially powerful approach to identify genetic variants that influence susceptibility to common complex diseases, but the results are often inconsistent. ${ }^{37}$ Inconsistencies may arise due to false positive studies, false negative studies, population stratification or true variability in genetic determinants among different populations. ${ }^{38}$ The present study has the following merits. (1) The analyses were based on three separate populations, including two large ones from Denmark and United Kingdom with power $\geq 80 \%$ as reported previously. ${ }^{39}$ Relatively small sample size is a reason for failure to detect and replicate associations across studies. (2) The design was a family-based analysis, which excluded the possibility that the significant associations detected were false positives due to the chance of population admixture and substructure. (3) The results of the significant associations were replicated in the different populations from the three countries with the same allele, the same SNPs and the same phenotypes. Usually, the association in a gene is replicated with a varied phenotype, with dissimilar poly- morphisms within the same gene, and with distinct alleles of the same variant. ${ }^{40}$ Thus, our replication of association was highly consistent, which made the significance of the detected associations reliable. (4) The IL18R1 gene was associated with a number of asthma-related phenotypes. Only a few genes have been shown to be associated with several asthma-related phenotypes. ${ }^{1}(5)$ The significance of some single SNP and haplotype associations remained after multiple corrections, reducing the possibility of false positive results.

Our study has several limitations. (1) Only SNPs in IL18R1 gene, but not in IL18R2 gene, were genotyped in our study. (2) Seven SNPs were selected based on the NCBI database but not from the LD tagging SNPs of all SNPs in IL18R1 gene. However, the selected SNPs were distributed in such a way as to capture most of the genetic information. (3) Only one functional SNP within the promoter was genotyped and studied. In order to test whether more functional SNPs are in LD with significant SNPs in our study with $r^{2} \geq 0.8,{ }^{41}$ we downloaded SNPs within IL18R1 from HapMap Caucasian data. Unfortunately, four nonsynonymous SNPs, rs11465635 (Arg > His), rs11465644 (Asn $>$ Lys), rs11465648 (Ser $>$ Asn) and 
rs12619169 (Gly > Arg) are monomorphic (Their alleles are G/G, C/C, G/G and G/G, respectively) in the Caucasian HapMap-CEU panel (see Supplementary Table 1S). Also, we found the same results of these SNPs from the NCBI database. Thus, we were unable to evaluate whether the significant SNPs in our study are in LD with these putative functional SNPs that may determine disease susceptibility. More work has to be done to identify functional variations more fully and to evaluate the effects of specific variants on gene function.

In conclusion, our genetic association studies, including analyses of both single markers and haplotypes, have revealed replicated significant associations between polymorphisms in IL18R1 gene and asthma, atopic asthma and BHR. Additional molecular functional studies are needed to investigate the role of variants in IL18R1 in the pathophysiology of asthma.

\section{Acknowledgements}

We gratefully acknowledge the sample management and custom genotyping groups in GlaxoSmithKline.

\section{References}

1 Ober C: Perspectives on the past decade of asthma genetics. J Allergy Clin Immunol 2005; 116: 274-278.

2 Busse WW, Lemanske RF: Asthma. New Engl J Med 2001; 344: $350-362$.

3 Thompson SR, Humphries SE: Interleukin-18 genetics and inflammatory disease susceptibility. Genes Immun 2007; 8: 91-99.

4 Nakanishi K, Yoshimoto T, Tsutsui H, Okamura H: Interleukin-18 regulates both Th1 and Th2 responses. Annu Rev Immunol 2001; 19: $423-474$.

5 Dinarello CA: IL-18: a Th1-inducing, proinflammatory cytokine and new member of the IL-1 family. J Allergy Clin Immunol 1999; 103: $11-24$.

6 Kalina U, Ballas K, Koyama $\mathrm{N}$ et al: Genomic organization and regulation of the human interleukin-18 gene. Scand J Immunol 2000; 52: 525-530.

7 Yoshimoto T, Mizutani H, Tsutsui H et al: IL-18 induction of IgE: dependence on CD4+ T cells, IL-4 and STAT6. Nat Immunol 2000; 1: $132-137$.

8 Hoshino K, Tsutsui H, Kawai T et al: Cutting edge: generation of IL-18 receptordeficient mice: evidence for IL-1 receptor-related protein as an essential IL-18 binding receptor. J Immunol 1999; 162: 5041-5044.

9 Torigoe K, Ushio S, Okura T et al: Purification and characterization of the human interleukin-18 receptor. J Biol Chem 1997; 272: 25737-25742.

10 Adachi $\mathrm{O}$, Kawai T, Takeda $\mathrm{K}$ et al: Targeted disruption of the MyD88 gene results in loss of IL-1- and IL-18-mediated function. Immunity 1998; 9: 143-150.

11 Kojima H, Takeuchi M, Ohta T et al: Interleukin-18 activates the IRAK-TRAF6 pathway in mouse EL-4 cells. Biochem Biophys Res Commun 1998; 244: 183-186.

12 Kojima H, Aizawa Y, Yanai Y et al: An essential role for NF-kappa B in IL-18-induced IFN-gamma expression in KG-1 cells. J Immunol 1999; 162: 5063-5069.

13 Matsumoto S, Tsuji-Takayama K, Aizawa Y et al: Interleukin-18 activates NF-kappaB in murine $\mathrm{T}$ helper type 1 cells. Biochem Biophys Res Commun 1997; 234: 454-457.
14 Higa S, Hirano $\mathrm{T}$, Mayumi $\mathrm{M}$ et al: Association between interleukin-18 gene polymorphism $105 \mathrm{~A} / \mathrm{C}$ and asthma. Clin Exp Allergy 2003; 33: 1097-1102.

15 Heinzmann A, Gerhold K, Ganter K et al: Association study of polymorphisms within interleukin-18 in juvenile idiopathic arthritis and bronchial asthma. Allergy 2004; 59: 845-849.

16 Shin HD, Kim LH, Park BL et al: Association of interleukin 18 (IL18) polymorphisms with specific IgE levels to mite allergens among asthmatic patients. Allergy 2005; 60: 900-906.

17 Dale M, Nicklin MJ: Interleukin-1 receptor cluster: gene organization of IL1R2, IL1R1, IL1RL2 (IL-1Rrp2), IL1RL1 (T1/ST2), and IL18R1 (IL-1Rrp) on human chromosome 2q. Genomics 1999; 57: 177-179.

18 Wjst M, Fischer G, Immervoll T et al: German asthma genetics group. A genome-wide search for linkage to asthma. Genomics 1999; 58: 1-8.

19 Malerba G, Lauciello MC, Scherpbier $\mathrm{T}$ et al: Linkage analysis of chromosome 12 markers in Italian families with atopic asthmatic children. Am J Respir Crit Care Med 2000; 162: $1587-1590$

20 Ober C, Cox NJ, Abney $\mathrm{M}$ et al: Collaborative study on the genetics of asthma. Genome-wide search for asthma susceptibility loci in a founder population. Hum Mol Genet 1998; 7 $1393-1398$.

21 Ober C, Tsalenko A, Parry R, Cox NJ: A second-generation genomewide screen for asthma-susceptibility alleles in a founder population. Am J Hum Genet 2000; 67: 1154-1162.

22 Pillai SG, Cousens DJ, Barnes AA et al: A coding polymorphism in the CYSLT2 receptor with reduced affinity to LTD4 is associated with asthma. Pharmacogenetics 2004; 14: 627-633.

23 Pillai SG, Chiano MN, White NJ et al: A genome-wide search for linkage to asthma phenotypes in the genetics of asthma international network families: evidence for a major susceptibility locus on chromosome 2p. Eur J Hum Genet 2006; 14: 307-316.

24 Roses AD, Burns DK, Chissoe S, Middleton L, St Jean P: Disease-specific target selection: a critical first step down the right road. Drug Discov Today 2005; 10: 177-189.

25 Wigginton JE, Cutler DJ, Abecasis GR: A note on exact tests of Hardy-Weinberg equilibrium. Am J Hum Genet 2005; 76: 887-893.

$26 \mathrm{O}^{\prime}$ Connell JR, Weeks DE: PedCheck: a program for identification of genotype incompatibilities in linkage analysis. Am J Hum Genet 1998; 63: 259-266

27 Horvath S, Xu X, Laird NM: The family based association test method: strategies for studying general genotype-phenotype associations. Eur J Hum Genet 2001; 9: 301-306.

28 Horvath S, Xu X, Lake SL, Silverman EK, Weiss ST, Laird NM: Family-based tests for associating haplotypes with general phenotype data: application to asthma genetics. Genet Epidemiol 2004; 26: 61-69.

29 Barrett JC, Fry B, Maller J, Daly MJ: Haploview: analysis and visualization of LD and haplotype maps. Bioinformatics 2005; 21: $263-265$.

30 Gabriel SB, Schaffner SF, Nguyen $\mathrm{H}$ et al: The structure of haplotype blocks in the human genome. Science 2002; 296: $2225-2229$.

31 Cardoso SP, Keen L, Bidwell J: Identification of two novel single nucleotide polymorphisms in the promoter of the human interleukin-18 receptor alpha. Eur J Immunogenet 2004; 31: $27-29$.

32 Watanabe M, Kaneko H, Shikano $\mathrm{H}$ et al: Predominant expression of 950delCAG of IL-18R alpha chain cDNA is associated with reduced IFN-gamma production and high serum IgE levels in atopic Japanese children. J Allergy Clin Immunol 2002; 109: 669.

33 Hoffjan S, Parwez Q, Petrasch-Parwez E, Falkenstein D, Nothnagel $\mathrm{M}$, Epplen JT: Association screen for atopic dermatitis candidate gene regions using microsatellite markers in pooled DNA samples. Int I Immunogenet 2006; 33: 401-409. 
34 Nadif R, Mintz M, Marzec J, Jedlicka A, Kauffmann F, Kleeberger SR: IL18 and IL18R1 polymorphisms, lung CT and fibrosis: a longitudinal study in coal miners. Eur Respir J 2006; 28: $1100-1105$.

35 Tiret L, Godefroy $\mathrm{T}$, Lubos $\mathrm{E}$ et al: Genetic analysis of the interleukin-18 system highlights the role of the interleukin-18 gene in cardiovascular disease. Circulation 2005; 12: $643-650$.

36 Kang M, Homer R, Gallo A et al: IL-18 is induced and IL-18 receptor $\alpha$ plays a critical role in the pathogenesis of cigarette smoke-induced pulmonary emphysema and inflammation. J Immunol 2007; 178: 1948-1959.

37 Lohmueller KE, Pearce CL, Pike M, Lander ES, Hirschhorn JN: Meta-analysis of genetic association studies supports a contribution of common variants to susceptibility to common disease. Nat Genet 2003; 33: 177-182.

38 Silverman EK, Palmer LJ: Case-control association studies for the genetics of complex respiratory diseases. Am J Respir Cell Mol Biol 2000; 22: $645-648$.

39 Zhu G, Vestbo J, Lenney W et al: Association of PTGDR gene polymorphisms with asthma in two Caucasian populations. Genes Immun 2007; 8: 398-403.

40 Ober C, Hoffjan S: Asthma genetics 2006: the long and winding road to gene discovery. Genes Immun 2006; 7: 95-100.

41 Carlson CS, Eberle MA, Rieder MJ, Yi Q, Kruglyak L, Nickerson DA: Selecting a maximally informative set of singlenucleotide polymorphisms for association analyses using linkage disequilibrium. Am J Hum Genet 2004; 74: 106-120.

Supplementary Information accompanies the paper on European Journal of Human Genetics website (http://www.nature.com/ejhg) 